\title{
INFLUENCE OF SPARK PLASMA SINTERING ON MICROSTRUCTURE AND CORROSION BEHAVIOUR OF WN43 MAGNESIUM ALLOY FOR BIOMATERIALS
}

\author{
${ }^{1}$ Mária ZEMKOVÁ, ${ }^{2}$ František LUKÁČ, ${ }^{2} J a k u b ~ C I N E R T, ~{ }^{3} J a n ~ B O H L E N, ~{ }^{1}$ Robert KRÁL, \\ ${ }^{1}$ Peter MINÁRIK
}

\author{
${ }^{1}$ Charles University, Faculty of Mathematics and Physics Department of Physics of Materials, Prague, Czech \\ Republic,EU, maria.zemkova@mff.cuni.cz \\ ${ }^{2}$ Institute of Plasma Physics, Czech Academy of Science, Prague, Czech Republic, EU \\ ${ }^{3}$ Magnesium Innovation Center, Geesthacht, Germany, EU
}

https://doi.org/10.37904/metal.2019.743

\begin{abstract}
Magnesium alloy Mg-4Y-3Nd was prepared by spark plasma sintering technique. The gas-atomized powder was sintered at temperatures in the range of $400-500{ }^{\circ} \mathrm{C}$ and holding time up to 10 minutes. The effect of sintering parameters, particularly sintering temperature and holding time, on the microstructure and corrosion resistance was investigated. The effect of sintering on the microstructure was investigated by scanning electron microscopy. Mechanical strength was investigated by microhardness measurements and corrosion properties were studied by linear polarization method. The results show that the sintering conditions seem to have only a minor effect on the final microhardness in the investigated temperature range. However, the increase in the sintering temperature caused recrystallization and grain growth accompanied by dissolution and reprecipitation of secondary phases particles. Due to these microstructural changes, the corrosion resistance was improved.
\end{abstract}

Keywords: Magnesium, spark plasma sintering, microstructure, corrosion resistance

\section{INTRODUCTION}

Magnesium alloys are being used as a structural material, mainly as mechanically less strained components in the construction of vehicles, electronics, sports equipment, etc. Nowadays, magnesium alloys are intensively studied and being developed for medical applications, particularly due to their biodegradable properties. However, biodegradable materials must fulfil many requirements. One of the crucial problems of magnesiumbased materials is the appropriate corrosion rate. The material must not decompose too fast and its mechanical properties must be kept during the required time. It has been shown that pure magnesium exhibits poor mechanical properties and too rapid degradation; therefore, magnesium alloys need to be used for such application [1].

Alloying elements improve the mechanical properties especially through the formation of secondary phases, by precipitation hardening and/or by solid solution strengthening. Moreover, some alloying elements, such as aluminum [2] or rare-earth (RE) metals [3,4] are able to increase the corrosion resistance and slow down the corrosion rate. Aluminum is an effective alloying element for improving both mechanical properties and corrosion resistance. Aluminum oxides fill pores in porous magnesium hydroxide layer, improve its stability and consequently decrease the corrosion rate [2]. The rare-earth metals are usually added in relatively small amounts in a form of mischmetals, where one or two elements dominate. Adding RE into Mg alloy is a usual way to enhance corrosion resistance. It was shown that yttrium can effectively decrease the corrosion rate, especially if it is homogenously distributed [5]. Nevertheless, the mechanism which is behind the corrosion resistance improvement is the same as in the Al-containing alloys - stabilization of the protective hydroxide film [6]. 
Magnesium-based parts of complicated shapes are usually produced only by casting, because of problems with forming which are associated with a limited ductility of magnesium. Powder metallurgy is an alternative manufacture method, which can produce the final product of complex shapes with minimum waste. Among the powder consolidation techniques, Spark Plasma Sintering (SPS) method exhibits very high sintering rate, which allows a decrease of holding time from hours to minutes [7]. Simultaneously, the application of elevated temperature and pressure leads to high densification of compacts. Due to the short holding times, the powder can be sintered without considerable grain growth and precipitation. In this report, we present the first results of the effect of Spark plasma sintering on the microstructure and room temperature corrosion resistance of magnesium alloy doped by yttrium and neodymium.

\section{EXPERIMENTAL METHODS}

Powder of magnesium alloy WN43 (Y - $4 \mathrm{wt} \%, \mathrm{Nd}-3 \mathrm{wt} \%)$ was prepared by gas-atomization at the Clausthal University of Technology, Germany. This non-commercial alloy was designed based on the latest literature review $[8,9]$ and is expected to have enhanced corrosion properties. Spark plasma sintering was carried out in a device type 10-4, Thermal technology LLC. Sintering was performed at three temperatures $-400{ }^{\circ} \mathrm{C}, 450$ ${ }^{\circ} \mathrm{C}$, and $500{ }^{\circ} \mathrm{C}$ and holding time of 3 and 10 minutes. The temperature was measured by a thermocouple placed in the graphite tooling in the vicinity of the sample. During the heating, the mechanical load was increased to the value of $100 \mathrm{MPa}$ and held during the sintering period. After the sintering, the load was released and compact was rapidly cooled down.

The microstructure of the initial powder and sintering material was analyzed using a scanning electron microscope (SEM) FEI Quanta 200F equipped with EDAX electron backscatter diffraction (EBSD) camera. The phases composition was investigated by X-Ray diffraction (XRD) using a diffractometer D8 Discover with CuKa source and NiK $\beta$ radiation filter. Microhardness of the sintering material was studied by fully automated system QNESS Q10 equipped with a Vickers indentor. Corrosion resistance was measured by the linear polarization method in the $0.1 \mathrm{M} \mathrm{NaCl}$ solution at the room temperature. The tests were conducted using the potentiostat AUTOLAB128N and three-electrode setup. The measurement was performed from $-150 \mathrm{mV}$ to $200 \mathrm{mV}$ with respect to the open circuit potential (OCP) and a constant rate of $1 \mathrm{mV} \cdot \mathrm{s}^{-1}$. Before each measurement, OCP was recorded for 10 minutes. Additional rotation of $300 \mathrm{rpm}$ was introduced to the samples in order to gain better homogeneity. At least three tests were performed for each sample.

\section{RESULTS AND DISCUSSION}

\subsection{Microstructure characterization}

The gas-atomized powder particles exhibited a typical spherical shape with the particle size up to $100 \mu \mathrm{m}$, see Figure 1a). The investigation of the cross-section showed the cell-like structure composed of $\mathrm{Mg}$ cells surrounded by the secondary phases, as shown in Figure 1b). The size of the cells strongly depends on the size of the individual powder particle, therefore, on the cooling rate. XRD measurement revealed that in the initial powder was only one secondary phase, which was identified as $\mathrm{Mg}_{3} \mathrm{Nd}$. Yttrium was the most probably dissolved in the magnesium matrix because even EDS investigation in SEM did not reveal the presence of any Y-rich particles.

Subsequently, six samples were sintered from the as-received powder in the temperature range of 400 $500{ }^{\circ} \mathrm{C}$ using holding time 3 and $10 \mathrm{~min}$. According to the SEM investigation, relative density close to $100 \%$ was achieved in all compacts. The microstructure investigation using SEM and EBSD revealed that the effect of sintering temperature was significant, the however effect of the holding time was almost negligible. The distribution of the grain size of the sample sintered at $400{ }^{\circ} \mathrm{C}$ was bimodal. We can see large grains with the size in a range of 50-80 $\mu \mathrm{m}$, which are surrounded by fine ones having the size of 3-5 $\mu \mathrm{m}$ (Figure 2a) and 3a)). The origin of this distribution lies in the recrystallization, which occurred preferably along original powder 
particles boundaries because the particles were partially deformed during the sintering. Increase in the sintering temperature to $450{ }^{\circ} \mathrm{C}$ caused coarsening of the grains, especially the fine ones, see Figure $2 \mathrm{~b}$ ) and $3 b)$. An additional increase of the sintering temperature up to $500{ }^{\circ} \mathrm{C}$ resulted in a further grain growth, which led to the formation of even more uniform distribution of relatively coarse grains, see Figure $2 \mathrm{c}$ ). The average grain size, calculated from EBSD data, for samples sintered at $500{ }^{\circ} \mathrm{C}$ for 3 and $10 \mathrm{~min}$. was $17 \mu \mathrm{m}$ and 15 $\mu \mathrm{m}$, respectively. Nevertheless, the data scatter was estimated as $2 \mu \mathrm{m}$, therefore, the values are the same within the statistical error.

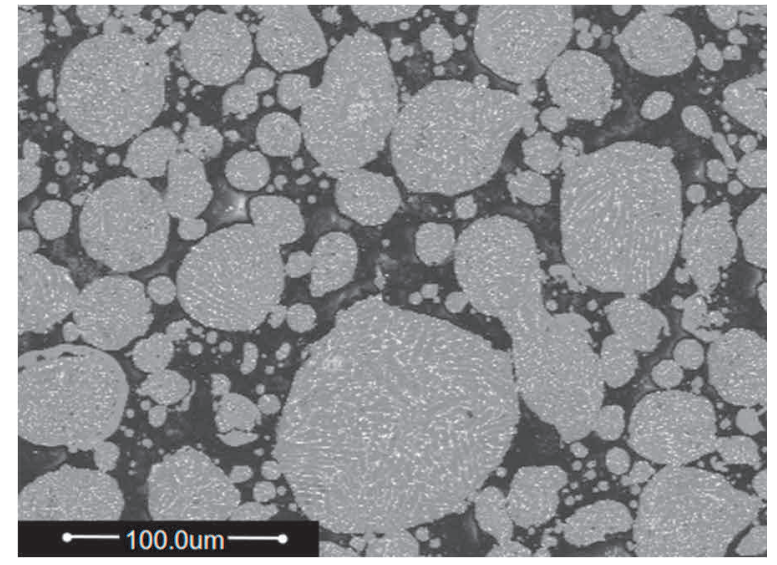

a)

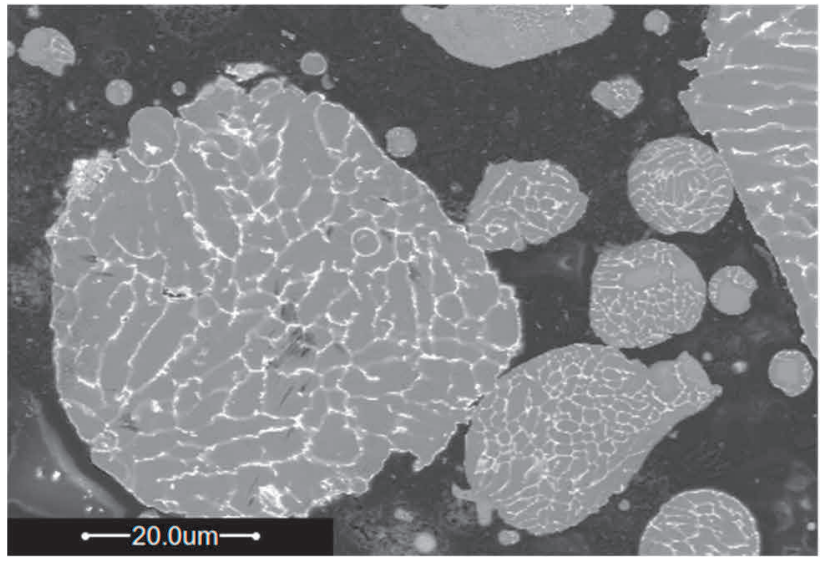

b)

Figure 1 a) The gas-atomized powder particles, (b) microstructure of the powder particles

One can see from the EBSD orientation maps a variation of orientation inside the large grains in samples sintered at low temperature. This information suggests the presence of residual stress in these samples. It is also apparent that the internal stress relaxes very quickly with the increasing sintering temperature. A similar effect of sintering conditions was previously observed in the AE42 magnesium alloy [10].

SEM observation of secondary phase particles showed changes in their distribution and size with the increasing sintering temperature. As can be seen from Figures 3 , the increasing sintering temperature caused the partial dissolution of the secondary phase particles. As indicate XRD measurement, the thermally unstable $\mathrm{Mg}_{3} \mathrm{Nd}$ phase present in initial powder was probably dissolved due to the elevated temperature and new stable phase of $\mathrm{Mg}_{41} \mathrm{Nd}_{5}$ was formed. However, this information needs to be confirmed by a precise identification of secondary phases in the transmission electron microscope.

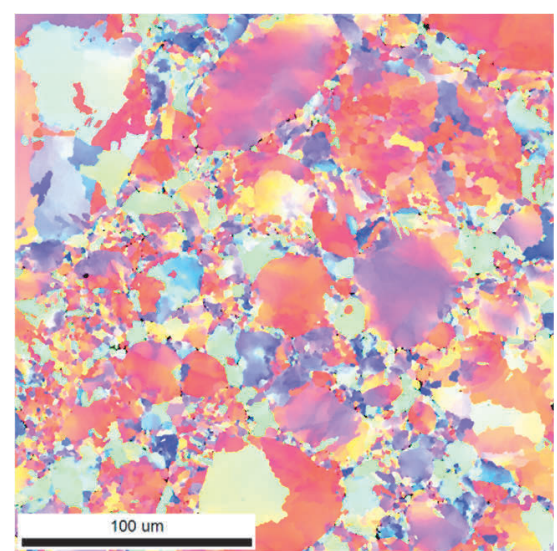

a)

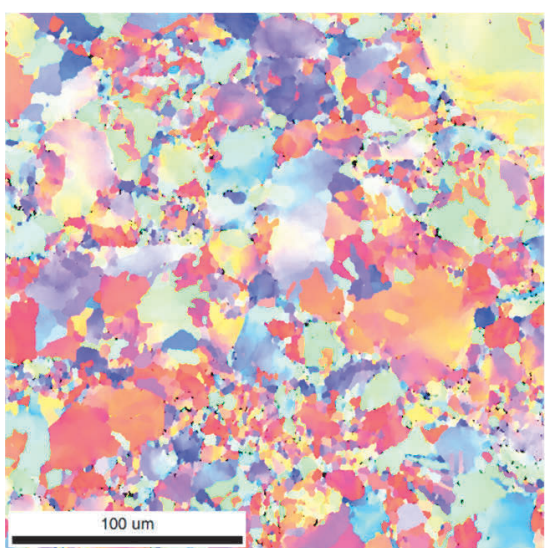

b)

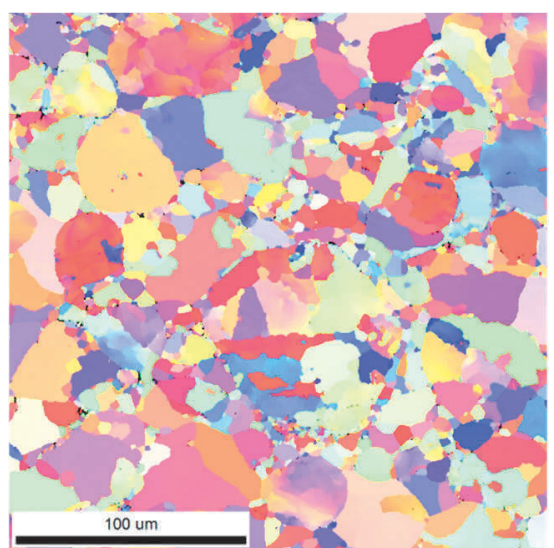

c) 


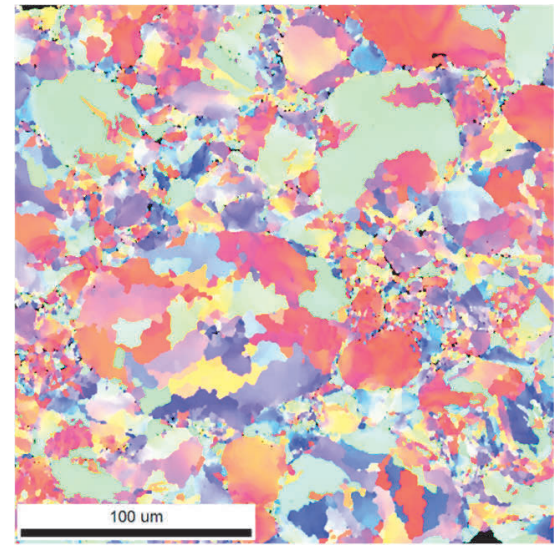

d)

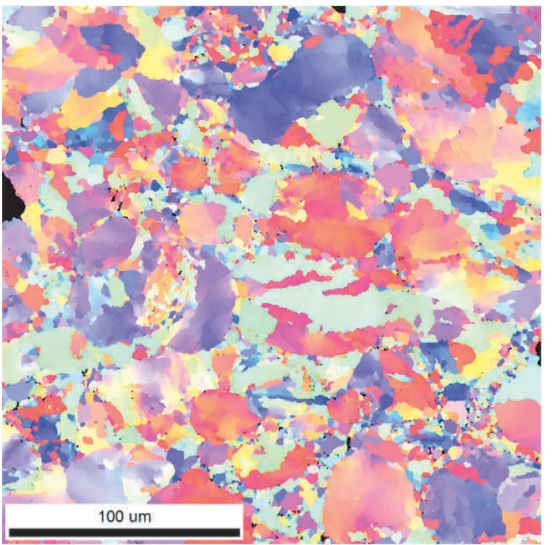

e)

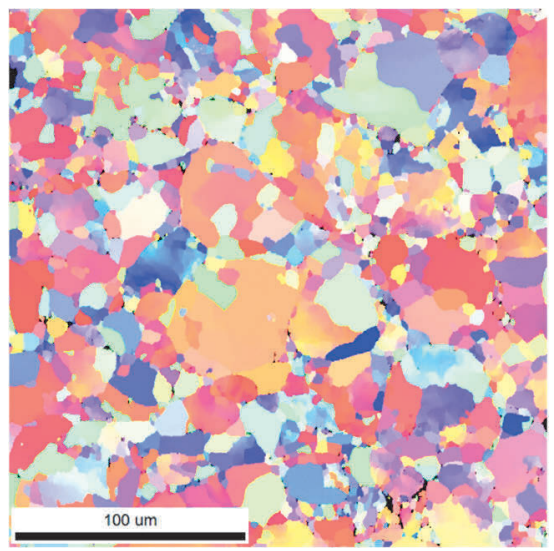

f)

Figure 2 EBSD orientation maps of samples sintered for 3 min at a) $400{ }^{\circ} \mathrm{C}$, b) $450{ }^{\circ} \mathrm{C}, \mathrm{c}$ ) $500{ }^{\circ} \mathrm{C}$, and sintered for $10 \mathrm{~min}$ at d) $400^{\circ} \mathrm{C}$, e) $450{ }^{\circ} \mathrm{C}$ and f) $500{ }^{\circ} \mathrm{C}$

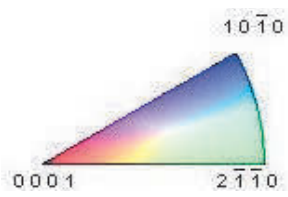

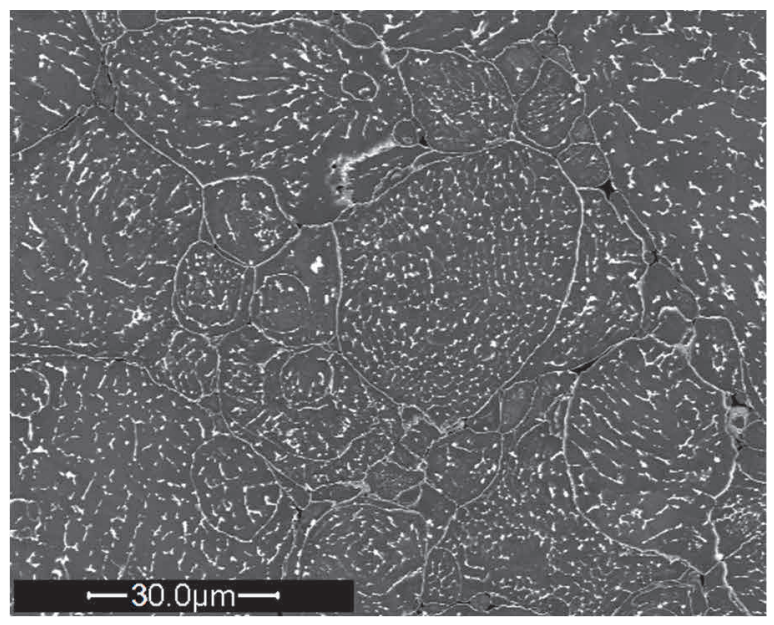

a) $400{ }^{\circ} \mathrm{C}$

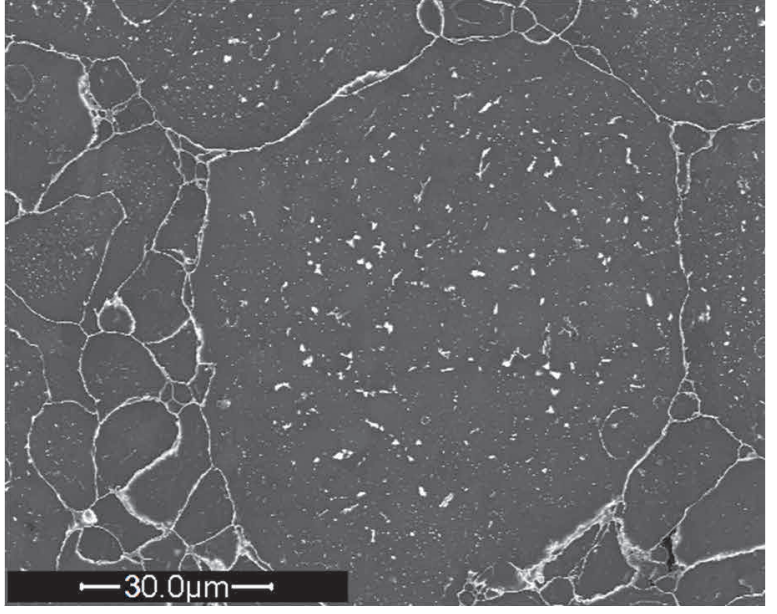

b) $500^{\circ} \mathrm{C}$

Figure 3 Difference in the phase distribution for different sintering temperature with holding time 3 min

\subsection{Microhardness and linear polarization resistance}

The sintering conditions seem to have an only minor effect on the final microhardness in the investigated temperature range regardless of holding time, see Table 1. However, as shown above, the grain size distribution with the increasing temperature changed significantly. Yttrium and neodymium, which are present in the WN43 magnesium alloy, are the most effective rare earth elements for the improvement of the mechanical properties by solid solution strengthening [11]. Because higher sintering temperature caused the dissolution of secondary phase particles its strengthening effect probably balanced the negative effect of grain growth and so decreasing volume of grain boundaries as well as decreasing of volume fraction of secondary phases.

Table 1 Values of microhardness measurements

\begin{tabular}{|c|c|c|c|c|c|c|}
\cline { 2 - 7 } \multicolumn{1}{c|}{} & \multicolumn{3}{c|}{3 min of holding time } & \multicolumn{3}{c|}{10 min of holding time } \\
\hline SPS temperature & $400{ }^{\circ} \mathrm{C}$ & $450{ }^{\circ} \mathrm{C}$ & $500{ }^{\circ} \mathrm{C}$ & $400{ }^{\circ} \mathrm{C}$ & $450{ }^{\circ} \mathrm{C}$ & $500{ }^{\circ} \mathrm{C}$ \\
\hline $\mathrm{HV}_{0.5}$ & $72 \pm 2$ & $71 \pm 1$ & $70 \pm 3$ & $71 \pm 2$ & $70 \pm 2$ & $70 \pm 2$ \\
\hline
\end{tabular}


The corrosion resistance of the WN43 magnesium alloy was measured by the linear polarization method, and afterwards, polarization resistance $\left(R_{p}\right)$ was calculated from the plot of electric current density and potential. The resulting values of polarization resistance are presented in Figure 4. A significant influence of the SPS parameters on the corrosion resistance was found. Both samples sintered at 400 ${ }^{\circ} \mathrm{C}$ exhibited a similar corrosion resistance. Subsequently, increased sintering temperature caused an increase of $R_{p}$ for both holding times. The corrosion resistance of magnesium alloys crucially depends on the microstructural state. Lattice defects such as grain boundaries [12] and secondary phase particles [2] as well as internal residual stress [13] are parameters that could have an effect on the severity of corrosion attack. As shown, due to the increasing

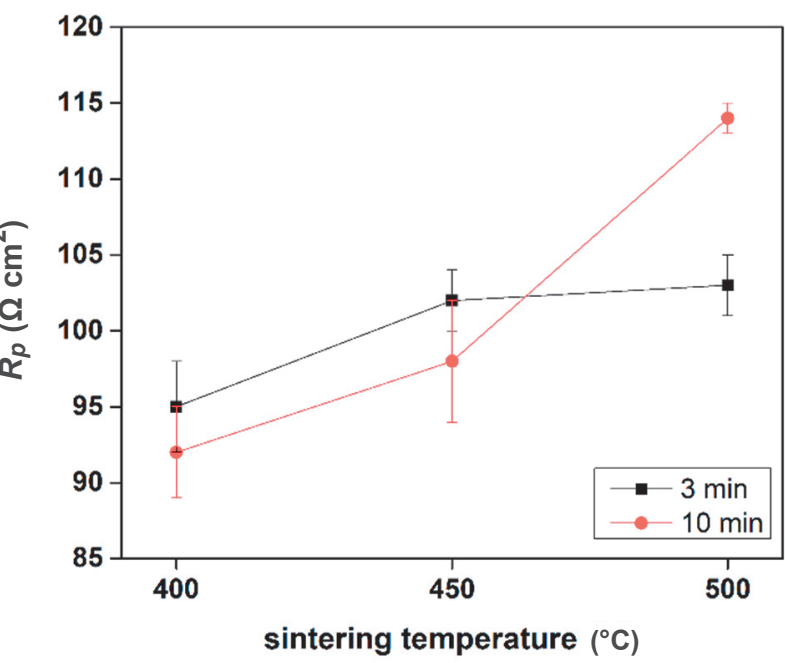

Figure 4 Evolution of the polarization resistance on the sintering temperature sintering temperature, a magnitude of residual stress decreases quickly. Additionally, higher temperature also caused grain growth accompanied by dissolution and globularization of finer secondary phases particles which results in decreasing of the volume of primary defects for corrosion nucleation. Because of the combination of these three aspects, the overall corrosion resistance was improved. However, the highest value of $R_{p}$ was found in samples sintered at $500{ }^{\circ} \mathrm{C}$ for $10 \mathrm{~min}$. Because the grain size and volume fraction of the secondary phase particles were similar for both samples prepared at $500{ }^{\circ} \mathrm{C}$, we assume that the decisive factor was internal residual stress. The magnitude of residual stress should be the lowest, as was reported in a previous study [10]. However, deeper investigation in this regard is still needed.

\section{CONCLUSION}

Magnesium alloy WN43 was processed by spark plasma sintering. Effect of the sintering parameters, particularly sintering temperature and holding time, on the microstructure, mechanical properties and corrosion resistance in $\mathrm{NaCl}$ solution was studied. It was found that variation of the sintering temperature as well as holding time did not affect the microhardness of the compacts; however, the significant changes of the microstructure were observed. The increasing sintering temperature caused grain growth, dissolution and globularization of finer secondary phases particles and continuous decreasing of the residual stress. These microstructural changes had a positive effect on the corrosion resistance and notable improvement of corrosion resistance was achieved.

\section{ACKNOWLEDGEMENTS}

This work was financially supported by the Charles University under the project GA UK no. 410119. P. M. acknowledges the financial support from the Czech Science Foundation in the frame of the project no. 18-19213Y.

\section{REFERENCES}

[1] POGORIELOV, M., HUSAK E., SOLODIVNIK, A. and ZHDANOV, S. Magnesium-based biodegradable alloys: Degradation, application, and alloying elements. International medicine and applied science. 2017. vol. 9, no.1, pp. 27-38. 
[2] MINÁRIK, P., KRÁL, R. and JANEČEK, M. Effect of ECAP processing on corrosion resistance of AE21 and AE42 magnesium alloys. Applied Surface Science. 2013. vol. 281, pp. 44-48.

[3] BIRBILIS, N., EASTON, M.A., SUDHOLZ, A.D., ZHU, S.M. and GIBSON, M.A. On the corrosion of binary magnesium-rare earth alloys. Corrosion Science. 2009. vol. 51, iss. 3, pp. 683-689.

[4] QIAN, M., HILDEBRAND, Z. and STJOHN, D.H. The loss of dissolved zirconium in zirconium-refined magnesium alloys after remelting. Metallurgical and Materials Transaction A. 2009. vol. 40, iss. 10, pp. 2470-2479.

[5] DAVENPORT, A.J., PADOVANI, C., CONNOLLY, B.J., STEVENS, N.P.C., BEALE, T.A.W., GROSO, A. and STAMPANONI, M. Synchrotron X-ray microtomography study of the role of $\mathrm{Y}$ in corrosion of magnesium alloy WE43. Electrochemical Solid-State Letters. 2007, vol. 10, iss. 2, C5-C8.

[6] LIU, M., SCHMUTZ, P., UGGOWITZER, P.J., SONG, G. and ATRENS, A. The influence of yttrium (Y) on the corrosion of Mg-Y binary alloys. Corrosion Science. 2010. vol. 52, pp. 3687-3701.

[7] MAMEDOV, V. Spark plasma sintering as advanced PM sintering method. Powder Metallurgy. 2013. vol. 45, iss. 4, pp. 322-328.

[8] LUKYANOVA, E., ANISIMOVA, N., MARTYNENKO, N., KISELEVSKY, M., DOBATKIN, S. and ESTRIN, Y. Features of in vitro and in vivo behaviour of magnesium alloy WE43. Materials Letters. 2018. vol. 215, pp. 308311.

[9] ZHENG, Y.F., GU, X.N. and WITTLE, F. Biodegradable metals. Materials Science and Engineering: R. 2014. vol. 77, pp. 1-34.

[10] MINÁRIK, P., LUKÁČ, F., CINERT, J., ŠAŠEK, S. and KRÁL, R. Effect of sintering temperature on microstructure and mechanical properties of AE42 magnesium alloy prepared by spark plasma sintering. In METAL 2018: 27th International Conference on Metallurgy and Materials. Ostrava: TANGER, 2018, pp. 1401-4406.

[11] TEKUMALLA, S., SEETHARAMAN, S., ALMAJID, A. and GUPTA, M. Mechanical properties of magnesium-rare earth alloy systems: A review. Metals. 2015. vol. 5, pp. 1-39.

[12] VRÁTNÁ, J., HADZIMA, B., BUKOVINA, M. and JANEČEK M. Room temperature corrosion properties of AZ31 magnesium alloy processed by extrusion and equal channel angular pressing. Journal of Materials Science. 2013. vol. 48, pp. 4510-4516,

[13] ZEMKOVÁ, M., KRÁL, R., ČíŽEK, J., ŠMILAUEROVÁ, J., MINARÍK, P. Influence of heat treatment on corrosion resistance of $\mathrm{Mg}-\mathrm{Al}-\mathrm{Zn}$ alloy processed by severe plastic deformation. Open Engineering. 2018. vol. 8, iss. 1, pp. 391-394.I 